\title{
Clinical Economics and Nursing
}

\section{Franz Porzsolt}

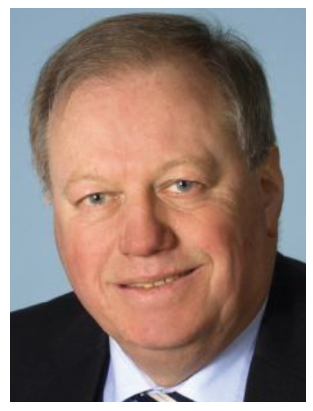

In one of our recent papers, we combined Donabedian's classical objectives of quality, i.e. structure, process and result ${ }^{(1)}$ with the clinical-economic perspectives of different subjects, i.e. individual, group-specific, and societal perspectives. Considering different perspectives - including the patients' perspective - is one of the core requirements of Clinical Economics (CLINECS). CLINECS means to apply economic principles to health care services. The meaning of the word "economic" must not be mixed up with the meaning of the word "commercial".

A complete economic analysis includes three parts: 1) "costs" i.e. what you have to accept such as hospitalization, side effects, the risk of a treatment or monetary costs, 2) "consequences" i.e. what you will get back such as a solution of your health problem, 3) "alternative ways of actions" which means you have always to compare costs and consequences of at least two or more possible actions. Clinical Economic decisions are a helpful tool to find the best of several possible solutions to the patient. In contrast, a commercial decision means to make profit, usually monetary profit to our own or our company's pocket.

Anchoring these demands in a new nursing structure law will not guarantee the desired elimination of existing shortcomings. Without claiming to be an expert in the field of nursing, I would like to propose some ideas that are still considered unfeasible by many, but should be brought up for discussion.

We should comprehend that good nursing is more valuable than many excellent high-tech solutions for which we expend a dizzying amount of resources. Many of these high-tech solutions can make life more comfortable, but are not essential. Nursing care is essential because a dignified life will no longer be possible for many people without good nursing care. In other words, nursing care is the price we have to pay for the lengthening of our life expectancy.

Three dramatic changes in our healthcare system could be necessary to meet this challenge. The best manager, the best nursing care, the best doctors, and the best politicians will tilt at windmills if even only one of these groups is not able to fulfill the required demands. Maintaining and regaining health requires teamwork. Health recognizes neither sectors nor specialist boundaries, which means that management, nurses, physicians, and politicians are not only to be equally involved on paper. Everyone is ultimately responsible for his/her field of endeavor. The ways of achieving this can vary greatly.

The concept of the Y-nurse was developed from the observation that there are numerous situations in daily nursing care that should be solved differently from the nursing perspective than from the physicians' perspective. The name of the letter ' $Y$ ' in English sounds like 'why', which is how the $Y$-nurse got the name. S/he is a highly qualified member of the entire team who is always (and only) called when there exist fundamental differences of opinion between doctors and nurses. The Y-nurses' task is to ask Y-questions, like, "Why, doctor, do you want to do that?" The $Y$-nurse is appointed by the board of medical directors but is responsible only to the CEO. Further details were described in a BMJ blog(2). In our opinion, transparency requires careful documentation of all $Y$-nurse assignments, as well as their conflicts, decisions and, finally, the results from different perspectives. The Institute of Clinical Economics (ICE) e. V., in cooperation with experts from the field of nursing at UNIOESTE (Universidade Estadual do Oeste do Paraná, Brazil) and from other Brazilian universities is developing a curriculum for suitable candidates to prepare for the tasks of a Y-nurse. 
Aside from established professional training in a subfield of nursing, the Y-nurse must know Clinical Economics i.e. $\mathrm{s} /$ he be able to lead an academic discussion. S/he must also, besides the usual leadership qualifications, be able to scrutinize and analyze the scientific foundations of clinical decisions. The necessary attitude, knowledge, and methods will be conveyed in service and regardless of the working site by the growing Center of Clinical Economics at UNILA (Universidade Federal da Integração Latino-Americana) and UNIOESTE, both at Foz do Iguaçu / Paraná, Brazil.

Detailed information about courses for interested people from any field of health care will be available in November 2015 through the office of the Center of Clinical Economics (fabiana.colombelli@unila.edu.br).

These two suggestions require considerable rethinking in the traditionally hierarchical teams of many of our healthcare facilities. Some progressive thinkers will presumably catch the ball and run with it, i.e., begin to apply the above suggestions. The essentials of the concept of Clinical Economics is summarized in a previous book ${ }^{(3)}$.

In general, however, measures are also needed to make the public fully aware that nursing is as necessary as reading, writing, and arithmetic. Therefore, we should think about introducing nursing care as a required subject in classes for 14-to-16-year-olds. Not everyone who learns to calculate should become a mathematician, and not everyone who learns about nursing should take up that profession. Just as you can't survive without understand arithmetic, we won't be able to survive if we are helpless in the face of a "nursing emergency".

\section{References}

1. Porzsolt F, Paschke S, Naegler H, Bruch h-P. Die Finanzierung des gesundheitlichen Mehrwerts setzt die Unterscheidung von Qualität und Nutzen voraus. Monitor Versorgungsforschung. [Internet]. 2015 [Acesso 22 ago 2015];4:39-43. Disponível em: http://www.monitor-versorgungsforschung.de/kurzfassungen/ kurzfassungen-2015/mvf-04-15/Qualitaet_Nutzen

2. Porzsolt F. The Y-nurse -pain in the neck or blessing for the team. BMJ Blog. [Internet]. (by BMJ group). Dec 29, 2010 [Acesso 17 jul 2015]; Disponível em: http://blogs.bmj.com/bmj/2010/12/29/franz-porzsolt-the-ynurse-pain-in-the-neck-or-blessing-for-the-team/

3. Porzsolt F, Kaplan RM, editors. Optimizing Health - Improving the Value of Healthcare Delivery. New York: Springer; 2006. p. 1-313.

Franz Porzsolt - Health Care Research, General and Visceral Surgery, University Hospital Ulm, 89070 Ulm, Germany. Institute of Clinical Economics (ICE) e. V., 89081 Ulm, Germany. E-mail: F.Porzsolt@gmx.de 